\title{
Using Nano Materials and Building Sustainability
}

\author{
Sherif Kamal Desouky ${ }^{(1)}$, Hussein Sabri Shanawani ${ }^{(2)}$, Razan Ibrahim Arafa ${ }^{(3)}$, Mai Mohammed Hammed ${ }^{(4)}$ \\ Department of architecture, faculty of Engineering, \\ Zagazig University
}

\begin{abstract}
Building facilities across the world, including Egypt, are exposed to many climate changes that have a negative impact on building materials and maintenance of their current finishing, which required the need to address the use of building materials with modern specifications that meet the criteria of sustainability. It is the building materials that interfere with the manufacture of nanotechnology, with its characteristics and features, that can face the effects of climate change and address the status quo buildings in many areas.

The present paper will discuss nanotechnology and identify its main materials, and the application of their use during building finishes, to achieve sustainability in accordance with global and local regulations.
\end{abstract}

Key words : The Nano technique, Nano Materials, sustainability standards, Sustainability of building finishing, Buildings facades, Nano Architecture

\section{INTRODUCTION}

We live now in a sustainable revolution in science and technology, one of the most prominent of which is nanotechnology, which has been destined to be the unique feature of the 21st century, this new technology has become a major focus of world attention. (1)

Sustainable architecture has emerged as one of the architectural trends due to changes in the natural environment and political, economic and social activities affecting various sectors of our time, most notably the construction sector (1) Construction technology has seen several successive advances that have led to the development of many traditional materials and the use of modern materials in facilities, some of which are not subject to sustainability standards, which has led to attention to sustainability standards in modern materials, making us more interested in clarifying sustainability standards to ensure that nanotechnology-based building materials meet sustainability standards.(2)

The nano technology influenced the construction methods and finishing materials used in the architectural facades, the combination of nanotechnology and natural building materials produced building materials with new features and features designed to conserve natural construction resources and materials and meet the criteria of sustainability, so nanotechnology has evolved from the way of thinking and aesthetic formation in the architectural facades, resulting in the emergence of a new architecture based on building materials that are processed using nanotechnology (3)
The research assumes that the development of the use of building materials based on nanotechnology production through a range of standards and controls that comply with the environmental standards and standards surrounding them will contribute positively to the realization of sustainable architecture principles and to addressing the damage that existing building materials have been unable to do on the facades of buildings without affecting design decisions

\section{RESEARCH PROBLEM}

Weather and environmental factors affect the deterioration of building finishes, due to the poor carrying capacity of these current materials to resist the effects of different climate, and their failure to meet sustainability criteria, resulting in the search for the use of building materials with characteristics that can resist climate impacts and process existing facilities.

\section{RESEARCH OBJECTIVES}

The search aims at the following

1. Learn what nanotechnology is.

2. Identify sustainable building assessment systems at various levels.

3. Learn about nanotechnology and materials applications in the field of finishing.

\section{RESEARCH METHODOLOGY}

The research uses description method, which collects facts, information and standards, that is included in the process of identifying the uses and materials of nanotechnology, during the safety of building's sustainability.

\section{NANO TECHNOLOGY}

The nanotechnology principle relies on the dots for the tiny atoms of any substance, manipulating it, moving it from its original positions to other positions, and then integrating it with atoms of other materials to form a crystalline grid to obtain high-performance, high-quality nano-particles.(3)

The interest in nanotechnology dates from 1996 to 1998 when the American World Technical Center (WTEC) undertook an evaluation study of nanotechnology research and its importance in all the various medical, military, computer, agricultural, engineering and other fields. (1)

\section{A. Nano}

A term derived from the Greek word Nanos means dwarf, defined in science as a micro-metric unit of measure.

This unit is used to express the dimensions of diameters, measures of atoms, particles of matter, compounds, and microscopic particles such as bacteria and viruses. .(4) 


\section{B. Science of nanotechnology :}

It is a science that is interested in studying how to deal with substances in their atomic and molecular levels with a scale of no more than 100 nanometers, and is interested in classifying atoms and molecules and studying their distinguishing characteristics, and studying related phenomena when downsizing them to interpret and rearrange them to create new materials. (5)

\section{Nano-Technology:}

It was defined by some scientists as "the technology that gives us direct control over substances and devices that are less than 100 nano-meters in dimensions by classifying, monitoring, measuring, and studying their properties", and another definition of nanotechnology as "nanotechnology, microscopic technology, or complementary technology" . (3)

\section{SUSTAINABILITY STANDARDS}

\section{A. Sustainable architecture}

The call for sustainable, environment-friendly architecture has begun, given the direct and indirect impact of existing projects on the natural environment and atmosphere as part of the sustainable development system, during their life cycle from the creation, work, operation and through the end-ofwork phase. (6)

This is defined as (architecture buildings designed, implemented and operated with sophisticated techniques and techniques that contribute to reducing environmental impact, reducing costs, especially operation and maintenance, while contributing to a safe and comfortable urban environment (6)

\section{B. Sustainable building Assessment Systems}

Sustainable buildings are evaluated according to many systems, whether global, regional or local, that define the requirements and standards to be available in buildings to obtain a sustainable building, the most important of which are:- (7)

1. Sustainable building Assessment System - United Kingdom - ( Breeam ).

2. Sustainable building Assessment System - United States of America - (Leedtm)

3. International Green Buildings Assessment System United States of America - (Green Globes )

4. Sustainable building Assessment System - Japan (CASBEE)

5. "Sustainable" pearl rating system - United Arab Emirates (ESTIDAMA)

6. Green pyramid assessment system - Egypt (GPRS)

\begin{tabular}{|c|c|c|c|c|c|}
\hline \hline BREEM & 15 & 12.5 & 6 & 19 & 10 \\
\hline LEED & 22 & 19 & 7 & 25 & 20 \\
\hline Green Globe & 20 & 10 & 8.5 & 38 & 11.5 \\
\hline CASBEE & 20 & 15 & 2 & 20 & 15 \\
\hline ESTIDAMA & 21 & 16 & 24.2 & 24.8 & 6.7 \\
\hline GPRS & 10 & 10 & 30 & 25 & 15 \\
\hline The average \% & $\mathbf{1 8}$ & $\mathbf{1 3 . 7 5}$ & $\mathbf{1 3 . 7 8}$ & $\mathbf{2 5 . 8}$ & $\mathbf{1 1 . 3 6}$ \\
\hline
\end{tabular}

Table (1) Sustainable building Assessment Systems (7)

Through the studies carried out, five basic determinants for the evaluation of sustainable buildings (energy efficiency, internal environmental efficiency, materials and resources, water efficiency, site sustainability) have been reached.

Table 1 shows the ratio of each of these determinants and the average of the previous systems, where the buildings are evaluated based on the average proportions of the determinants of those systems (7)

\section{Criteria for achieving sustainable architecture}

We note from the table (1) the most important determinants and criteria for sustainability of local and global systems and identify the percentage of each element of these standards, and here we address the most important determinants of building and finishing materials that achieve sustainability of these standards as follows:

1. How to achieve sustainability of the site (8)

- Take into account the direction of the building and make the most of the natural lighting and ventilation.

- Optimal use of the sun and wind power and the promotion of reduced negative sunlight for ventilation and natural lighting.

- Reduce the environmental impact of harmful gases and purification by preserving plants or using substances that can react to harmful gases and reduce their impact

2. How to achieve energy efficiency (9)

- Using low latent materials

- Use thermal insulation

- $\quad$ Provide plenty of natural light

- Use alternative energy sources and high efficiency devices

3. How to achieve water efficiency (6)

- Rationalization of water use .

- Reuse the water of rain

- Use of water-less finishing elements in the construction process.

- Maintaining and purification of rainwater and using building materials that do not affect water and maintain its survival.

4. Efficient building materials (7)

- Use recyclable and remanufactured materials as well as materials containing recycled materials

- Reduce the use of substances with a negative impact on the environment such as volatile organic compounds, toxic substances such as asbestos, lead, and substances containing compounds harmful to the ozone layer.

- use of reusable materials without resort to manufacture such as glass, foam and stone

- Material durability and durability, which increases life

5. Quality of interior (6)

- $\quad$ Provide plenty of natural light

- Help provide thermal comfort by considering the structure's fabric or using suitable temperature and cold protection materials

- Offers sound isolation to isolate the building from the surrounding outdoor environment

- Maintains the air purity surrounding the interior environment 
Based on the sustainability criteria, we are now addressing materials that can help achieve sustainability of buildings that are used in finishing buildings and comparing them with other materials

\section{NANOTECHNOLOGY APPLICATIONS IN CONSTRUCTION FINISHING}

Nano technology has influenced construction methods and building finishing materials, especially in its facades, the combination of nanotechnology and natural building materials has produced building materials with new characteristics and features designed to conserve natural building resources and materials and achieve sustainability standards, (6) so Nano technology has evolved from the way of aesthetic thinking and shaping in architectural facades, resulting in the emergence of a new architectural appearance based on these materials to meet architectural processors and user requirements, and the following materials will be addressed as follows for applications (7)

\section{A. Nano-concrete cladding}

The traditional concrete is mixed with specific silica ratios ( $\mathrm{SiO} 2$ with other materials that make up it, these percentages determine the density of concrete, (7) its carrying force for pressure and its ability to withstand and durability as a number (1), and to improve the properties of concrete to make it a material that helps to achieve sustainability of the building nanotureses are added as follows :

1. Adding $3 \%$ of nano silica increases the force of pumping and bending from cement tuna by $10 \%$ : $25 \%$ and reduces the absorption of sound by $240 \%$

2. Reduce carbon dioxide emissions with nano-silica

3 . The addition of $2 \%$ calcium disilicon increases the tensile strength in the cement paste by about $40 \%$

4. Adding titanium dioxide by $5 \%: 10 \%$ increases the pressure force of concrete by $26 \%: 35 \%$

5. Titanium dioxide helps self-clean and purification of the air

Note from the above that the addition of nanoparticles sustainability is achieved through air purification, sound insulation (which increases internal user comfort), and concrete trim has been used as No. 1 in the Italian Lyobell Church, with titanium dioxide added to help purify the surrounding air as well as the life of the building, so the addition of the concrete added nanoparticles helps to sustainability by achieving site sustainability and increasing the efficiency of the materials used (11)

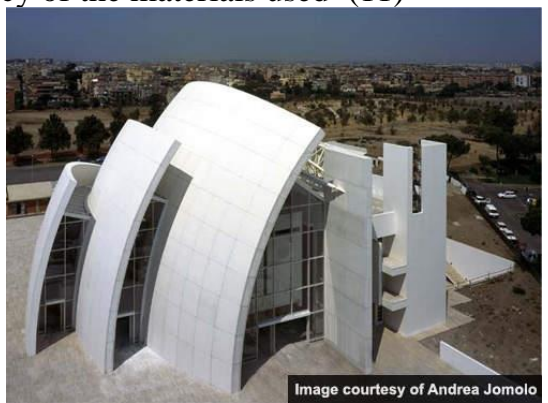

Photo (1) of the Lyobel Church in Italy and its use of nanoconcreteTransparent concrete (10)

\section{B. Transparent concrete}

It is a concrete that moves light from the outside to the inside to make the building look like a large window, thus saving energy by using less industrial light, as transparent concrete has ordinary concrete features and with the addition of nanoparticles allowing for external light to be drawn in as shown in Figure 2, so when adding nanoparticles mentioned in previous concrete, the properties of concrete are improved and the transparency is maintained so that transparent concrete uses less energy in the pre-cooling and thermal light category (12)
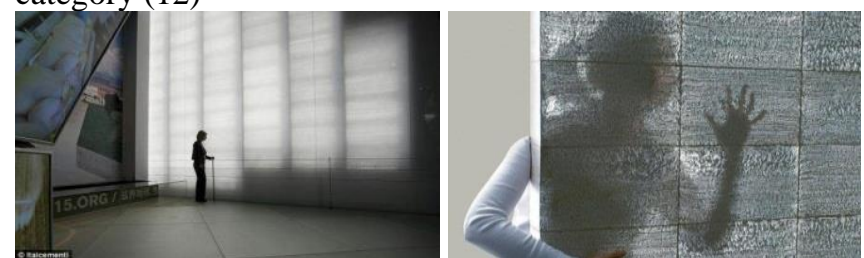

Photo ( 2 ) shows the possibility of transparent concrete to receive the light of the surrounding environment externally for the interior of the architectural space (12)

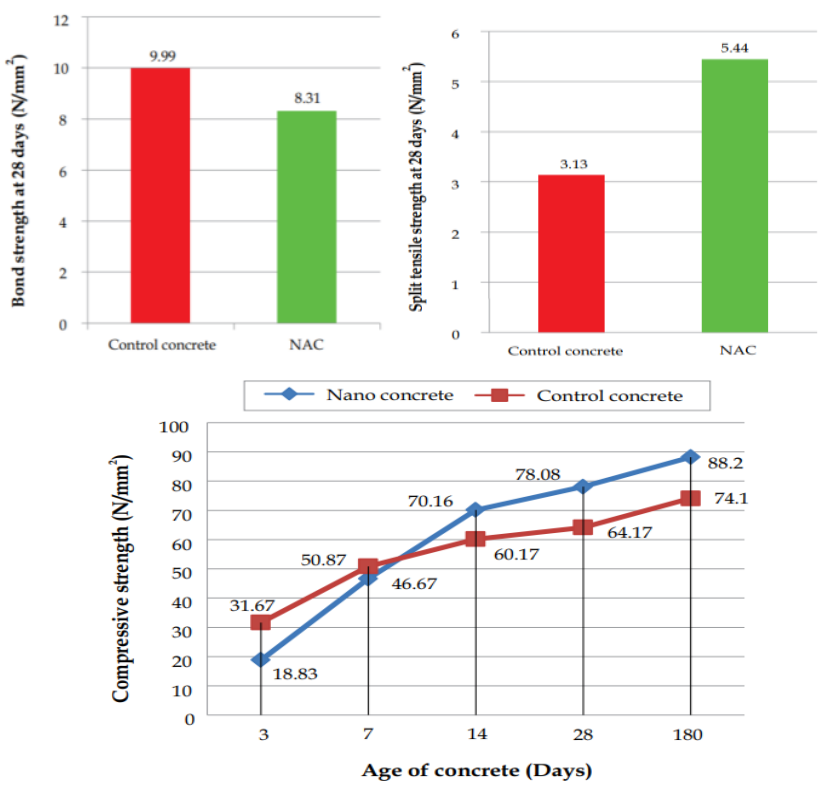

Figure (1) shows a comparison of standard and added concrete with nanoparticles (13)

We note from the Fig (1) that the addition of nanoparticles is more powerful and durable for the factors of pressure and tension, which increases the life of the concrete, making us material to help achieve sustainability of the buildings

\section{Nano-treated wood}

Wood is one of the most widely used structural materials, using nanotechnology to process and improve its molecules, and wood is considered sustainable, but there is some lack of survival, so nano materials are added to wood, the most important of which are the following (14)

Aluminum nanoparticles: Increase the hardness of the wood and its resistance to corrosion and scratch.

- Iron oxide and nanotitanium dioxide: Protect wood from ultraviolet radiation and resist fungi, mold and algae, thereby increasing its time-age. 
- Tesueran - Nano Salica: Increases the hardness of the wood, prevents water leakage and does not release steam.

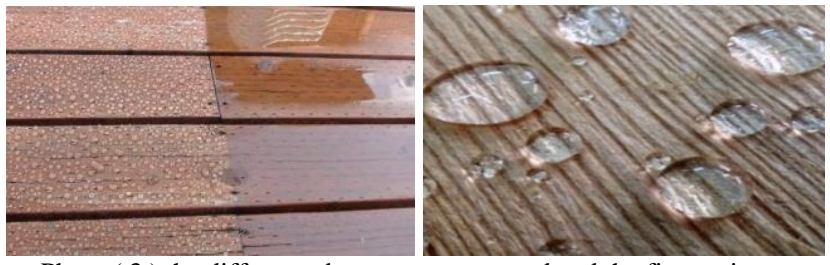

Photo ( 3 ) the difference between nano-wood and the first resistance to water (14)

Note from Figure 3 that the addition of nanoparticles to wood prevents the absorption of wood by water and keeps the drop of water as unabsorbed, which increases the life of wood and protects it from surrounding atmospheric factors such as moisture, mold and bacteria, increasing its assistance in achieving sustainability standards for buildings (14)

\section{Easy to clean - surfaces}

Water-proof surfaces, soft-touch, have low static energy resulting in reduced surface adhesion, where water forms droplets immediately and then quickly escape, it is also oilresistant, and generally when it enters the production of surfaces it is easier to clean and some examples of easy-toclean surfaces (1) (ceramics - calderming) photo (4)

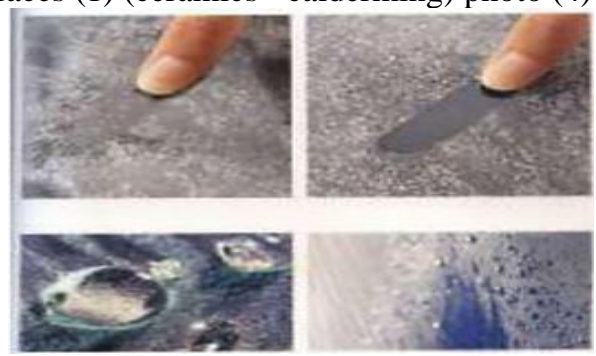

Photo (4) Comparison of easy-to-clean surfaces and normal surfaces (1)

In 2005, easy-to-clean tiles on the façade of the Center of the Boxing Mohamed Ali were reinforced by the addition of glass salt, which makes them more durable and has been experimented with these plaas, determining their sustainability of the site and making it clear that 1,000 square meters of these plaas are equivalent to the impact of 70 medium-sized trees on the purification of the surrounding environment (15)
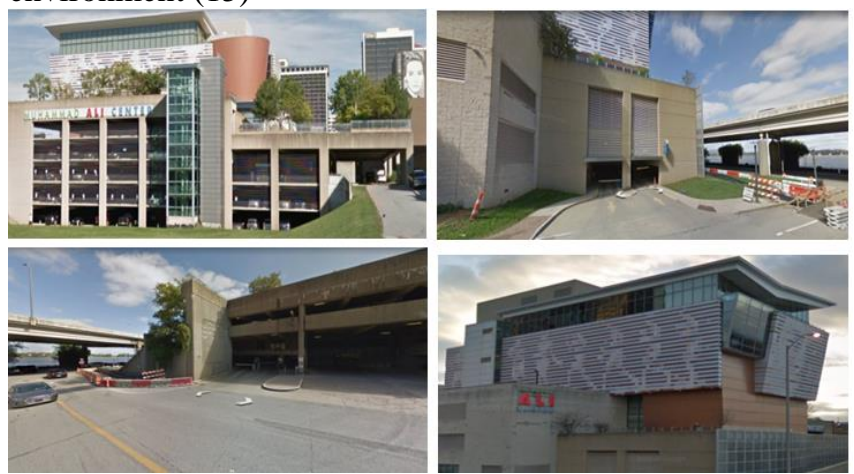

Photo ( 5 )the Center of Boxing Mohammed Ali, Kentucky, America, and the surrounding buildings (27)

From photo (5), we notice the deterioration of the interfaces surrounding the center of Muhammad Ali, changing the surface color and accumulating dust and salt on them, but the center's facades remain clean due to easy-clean plates

\section{E. Nanotechnology-treated glass}

The glass material is the most important material used in shaping the exterior facades because it gives the building a perfect appearance, it is easy to maintain and provide natural lighting and a suitable climate for indoor voids, (16) and nanotechnology has been used to provide many types of treated glass (17)

1. The heat-sealing glass by placing a thin layer of nanosecond between the plates

2. the glass is self-cleaning by using titanium dioxide paint.

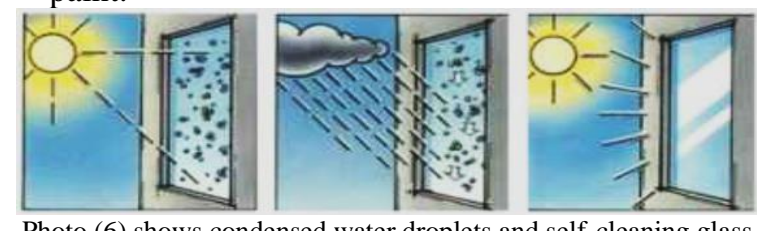

Photo (6) shows condensed water droplets and self-cleaning glass capabilities for immediate disposal (1)

3. the solar-reflective glass above the Pfc by painting a transparent film that is facing the Sun to prevent harmful sunlight from entering, so the paint process must be done during the manufacture of glass because the paint at a later stage makes the metal layer unable to withstand the weather (18)

4. Smart glass (electric variable color): It allows users to control the intensity of light and temperature within the space, changing from transparent to translucent glass and partially blocking visibility while keeping the light ratio in place (15)
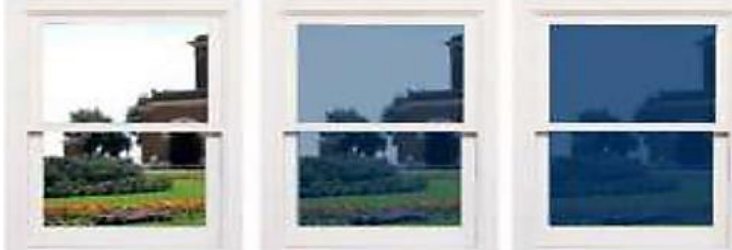

Photo (7) The smart glass, which can control the intensity of light and heat inside, changes from transparent glass to translucent and partially prevents visibility (15)

5. Flame-proof glass : a progeny silic acid used for a number of purposes including nanoparticles, or nanosilicas, is greater than only $7 \mathrm{~nm}$, and because of its relatively large area, it is highly interactive, as a number (7). $91 \%$ light transition per $1 \mathrm{~cm} 2$. Thermal conductor $(0.71 \mathrm{~W} / \mathrm{m} 2$ Kelvin $)$. (1)

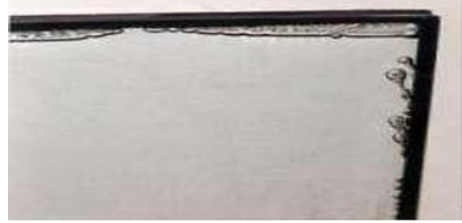

Photo (8) shows the anti-flame, a viscous material that does not affect visibility that shows its operation when exposed to the fire for an extended period of time (1)

A study of the Cairo National Planning Institute building has been conducted and comparisons of glass types that can be used in the processing work to achieve 
sustainability of that building have been shown and the Design Builder program used for comparison work, note that: (19)

1. Average annual temperatures are $21^{\circ} \mathrm{C}$.

2. Highest temperature recorded is $45^{\circ} \mathrm{C}$.

3 . The average wind speed is $12 \mathrm{~km} / \mathrm{h}$.

4. The average dew point is $11^{\circ} \mathrm{C}$.

5. Average relative humidity in the morning $76 \%$ and evening $38 \%$

6. The light intensity required in the building is 300 $1 \mathrm{x}$

7. Minimum ventilation per capita of 10 liters/s/person

8. Temperature at which normal ventilation is allowed: $22^{\circ} \mathrm{C}$.

Using the Design Builder program and the Egyptian code, the following comparison table between glass types was reached

\begin{tabular}{|c|c|c|c|c|}
\hline Glass types & SHGC & $\begin{array}{c}\text { Light } \\
\text { Trans }\end{array}$ & U-Value & thickness \\
\hline $\begin{array}{c}\text { Single low-light } \\
\text { glass (normal) }\end{array}$ & 0.72 & 0.811 & 3.779 & $6 \mathrm{~mm}$ \\
\hline $\begin{array}{c}\text { Color reflective } \\
\text { electro-chromic } \\
\text { glass (nano-glass) }\end{array}$ & 0.155 & 0.137 & 1.76 & $13 \mathrm{~mm}$ \\
\hline $\begin{array}{c}\text { Thermal sealing } \\
\text { glass (nano-glass) }\end{array}$ & 0.158 & 0.095 & 2.30 & $6 \mathrm{~mm}$ \\
\hline $\begin{array}{c}\text { UV reflective } \\
\text { glass (nano-glass) }\end{array}$ & 0.161 & 0.053 & 2.301 & $6 \mathrm{~mm}$ \\
\hline
\end{tabular}

Table ( 2 ) shows the comparison of U-value, Light Trans, ShGC
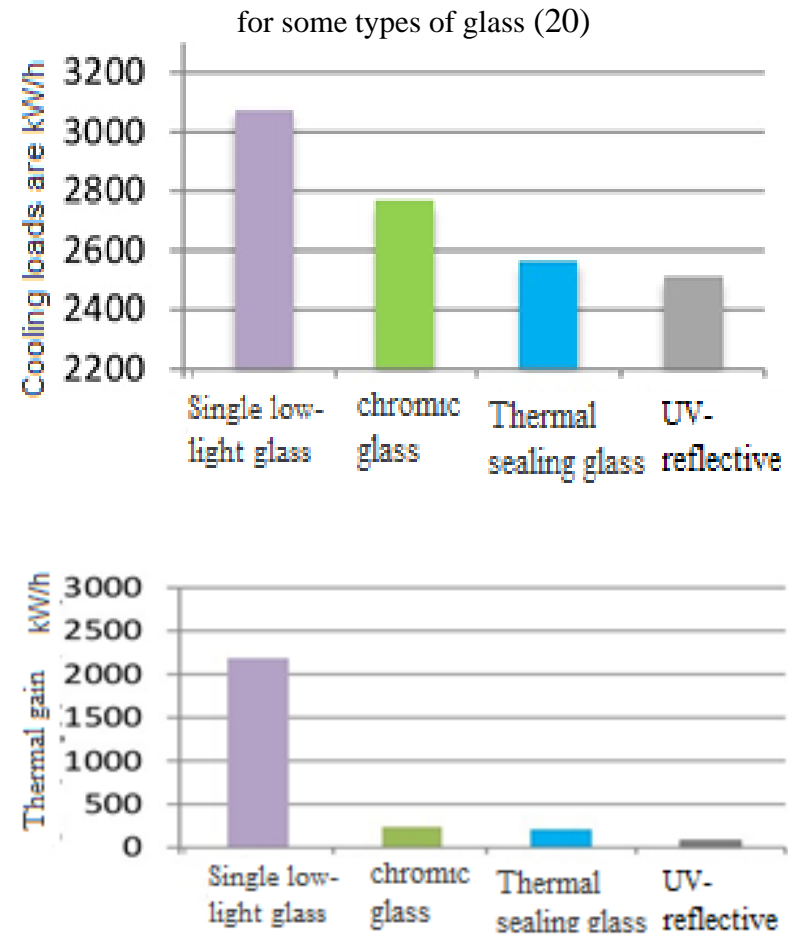

Figure (2) Thermal gain and annual cooling loads for glass substitutes using the Design Builder program (19)

We note from past experience on the glass that nanotechnology-processed glass greatly helps to achieve energy sustainability as it saves a lot of energy, unlike its counterparts in ordinary glass

\section{F. nano-paintting}

Several nanoparticles were produced to solve many problems of architectural origin, so care had to be taken to protect external architectural surfaces to be highly efficient, the most important of which was used in the finishing process

1. Self-cleaning (lotus flower effect)

Her idea was based on the work of the surfaces of the lotus plant, when water drops fall on the surface of the plant leaves, she cleans them immediately without the surface becoming wet (20)
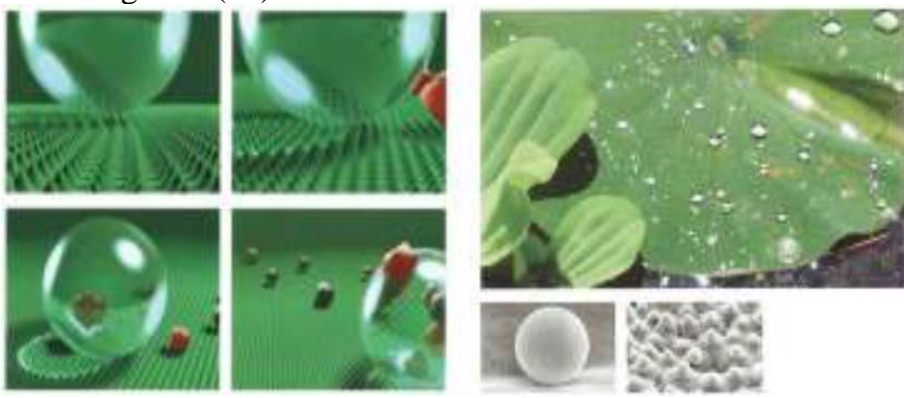

Photo (9) It illustrates the idea of the effect of lotus flower and the presence of protrusions on surfaces with a nanometer, where it carries droplets of water that in turn take dust with it to fall (21)

2. Self-cleaning using photocatalysis

Depends on the interaction of light (UV) with titanium dioxide (tiO2), so that light is used as an activated substance to become highly reactive to remove dust (22)

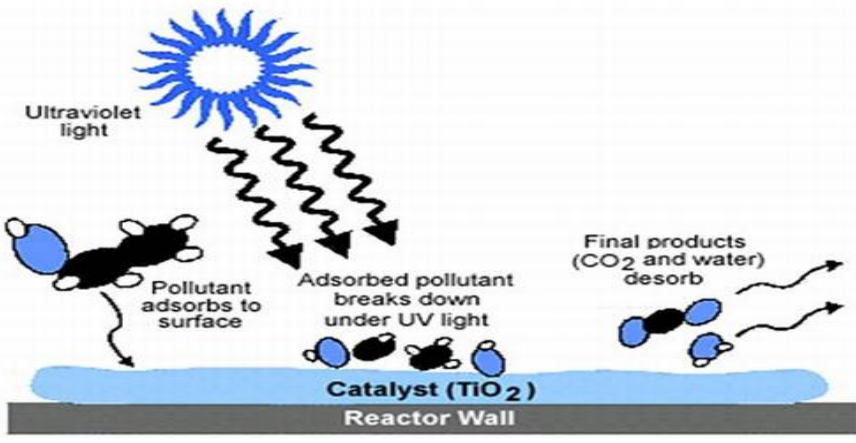

Photo (10) No dust overlays on surfaces using light stimulation (22)

3. Anti-fog coating

The paintwork with a very thin layer of titanium dioxide to analyze the droplets of water and fog for a very thin film that is not visible, is used extensively with glass windows (23)
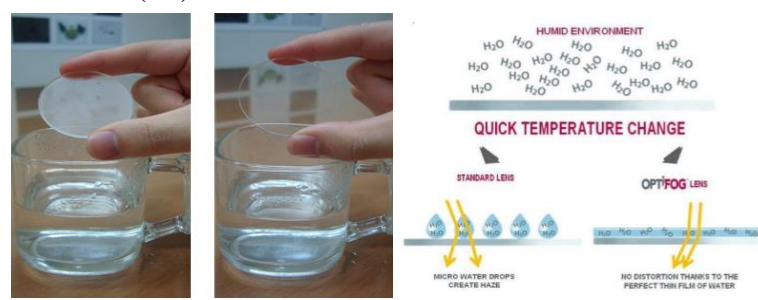

Figure (3) the concept of anti-fog coating (23)

\section{Anti-writing paint}

It is able to easily remove writing from walls and protect materials such as bricks, sandstone and limestone from absorbing writing colors, as well as surface protection from scratches caused by drawing friction and writing on walls $(24)$ 


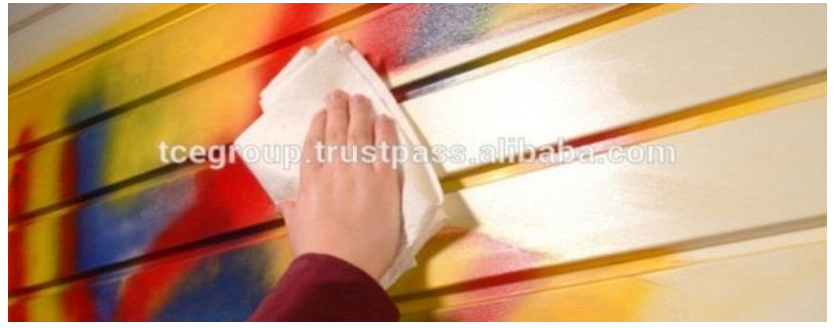

Photo (11) shows that drawings are not sticking to the antitype paint (25)

\section{Anti-bacterial coating}

They are able to resist the formation of bacteria on the walls and protect substances because they can analyze organic substances into un-harmful waste and dust, with the help of silver particles in the nanometer that have antimicrobial properties (26)

A wall experiment was conducted to determine the efficacy of nanoparticles on the facades of buildings, and the experiment was three months long, with space taken from the wall and well cleaned, part painted nanoparticles painted, and the other part painted with ordinary paint, and the effect of climate factors on this sample of the experiment was shown to be clean while the other part was affected by the surrounding factors and the image (12) shows the effect of the factors surrounding the paint period (1)
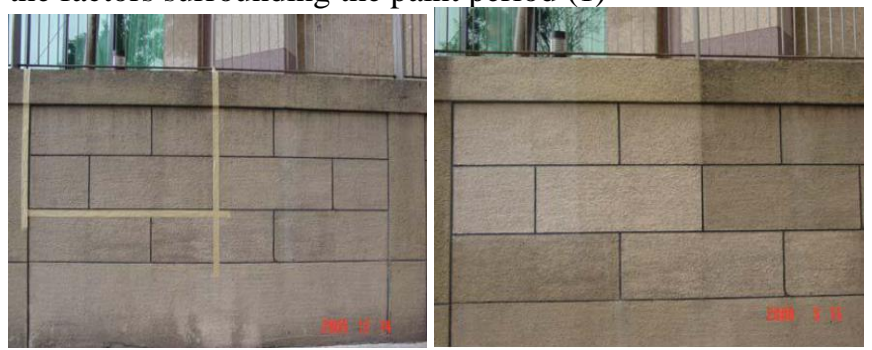

Photo (12) The image on the left on 14 December 2005 and on the right on

15 March 2006 is an experience that demonstrates a comparison of the nano coating that is easy to clean using photosynthesis and other paints (1)

\section{CONCLUSION}

In presenting research, which is included in the facts, information and criteria for the use of nanotechnology materials, and the sustainability of buildings, the following current and future findings and recommendations can be inferred :

1. The principle of nanotechnology depends on the acquisition of nanoparticles by nanoparticles, moving them from their original positions to other locations, to integrate other material seeds, which in turn form a crystal grid of nanoparticles with high-performance properties

2. There have been developments in the production of materials with new characteristics, which will achieve environmental sustainability and can be used in Egypt.

3. The development of nanotechnology through building techniques and building finishing materials can lead to the emergence of a new architectural look and treatments, tailored to the user's requirements and the sustainability of the building.

4. In addition to the development and production of concrete concrete upholstery, transparent concrete, nano-treated wood, easy-to-clean surfaces, nano-treated glass, flame-proof glass, fog, writing and then bacteria, nanoparticles, photosynthesis, photosynthesis... And more.

5. The paper found the criteria and determinations of the main and sub-elements of the mechanism for assessing the use of nanoparticles within the framework of the sustainability of buildings to address the adverse effects of atmospheric factors

As part of the consolidation of the previous results, the research recommends:1. The importance of architects following developments in the production of new nanoparticles associated with the architectural and construction aspects, in order to enhance environmental

sustainability.

2. The importance of following developments in the production of nanoparticles with new features, achieving environmental sustainability. 3. The importance of highlighting architecture for the uses of nanotechnology during construction methods and building finishing materials, to suit the contemporary processing of these developments.

\section{REFERENCES}

[1] Fahd Hemeida, "green nanoarchitecture", master of architecture, Alex university, Egypt, P 2-38, January 2010

[2] Samar Z Moh, "Nanoscience And Nanotechnology in architecture, International Journal of Scientific \& Engineering Research, Volume5, Issue 11, P 479-482, November-2014

[3] Iskenderani Mohammed, "Nanotechnology for Tomorrow better", Kuwait, National Council for Culture, Arts and Literature, 2010, P 1:5

[4] Youssef Ali, "Nano Technology and future Applications", Syria, National Center for the Eximents, 2015, P 4

[5] Arafa R, "Using Nanotechnology to Devolop the hospital Building performance", degree of doctor of architecture, Zagazig university, Egypt, P 56, April 2017

[6] Mari Sayyed Mansour, "toward an integrated system to develop the use of building materials as an entrance to sustainable architecture in Egypt", Masters, Faculty of Engineering, Matriyah, Helwan University, 2010, P 21

[7] Saif Al-Nasr Mohamed, "the role of nanotechnology Applications in achieving Sustainable Architecture", Egypt, Al-Azhar Newspaper, issue 42, 2017, P 310:327

[8] Attar Mohamed Ismat, "the current methodology for assessing sustainable buildings in Egypt between possibilities and obstacles", Journal of Engineering Sciences, Assiut University, Egypt, 2018, P 263:281

[9] Al-Ra'i Muhammad Mukhtar, "the sustainable architecture from a local perspective is an Egyptian experience for building using compressed soil bricks in desert areas", Saudi Arabia, Riyadh, Second Housing Seminar "the Facilitator Home." , 2004

[10] Jubilee Church : https://www.designbuild-network.com/projects/jubileechurch-rome/ , 10/11/2019

[11] Sai Kiran Vangavallu, 2016, "Comparison of mechanical properties of Nano concrete with conventional high strength concrete" , The Indian Concrete Journal , P 97:99

[12] transparent concrete http://shade.ms/ar/2770-2/ , 1/11/2019

[13] Sai Kiran Vangavallu, 2016, "Comparison of mechanical properties of Nano concrete with conventional high strength concrete" , The Indian Concrete Journal , P 97:99

[14] Michael F. Ashby, Paulo J. Ferrira, Daniel L. Schodek, 2009 ," nanotechnologies and design" , Oxford, UK , P 408 
[15] Leydecker Sylvia. "Nanomaterials in Architecture, Interior Architecture and Design". Birkhauser Basel, Boston, Berlin, PP57-86, 2008

[16] Michael F. Ashby, Paulo J. Ferreira, Daniel L. Schodek. " Nanomaterials, Nanotechnologies and Design. An Introduction for Engineers and Architects ", ButterworthHeinemann, ISBN (9780080941530), P 407:423, 2009.

[17] Ritter Axel. " Smart Materials in Architecture, Interior Architecture and Design", Walter de Gruyter, Berlin, ISBN (3764382279, 9783764382278), P 73:80, 2007

[18] Johansen John, " Nanoarchitecture: A New Species of Architecture ", Princeton Architectural Press - New York, ISBN (1568983018, 9781568983011), P 151:157, 2002

[19] Dina Gharib, "toward applying sustainability principles for the development of existing administrative buildings in Egypt", Masters, Ain Shams University, Faculty of Engineering, Department of Architecture,2011, P 159:170

[20] Edwin Nun, Markus Oles and Bernhard Schleick, " Lotus effect - surface ", Macromolecular Symposia, Volumne 187, Issue 1, PP 677-682, October 2002

[21] Surface allows self-cleaning : https://asknature.org/strategy/surface-allows-self-cleaning/

[22] New photocatalyst shows promise for fuel production : https://www.chemistryworld.com/news/new-photocatalystshows-promise-for-fuel-production/9529.article

[23] Nagwan Shehata "Nanotechnology's Effect in Development of - Interactive Interior Design" Visual arts between stability and variation conference, Faculty of Finearts, Alexandria University 2007

[24] Gyula Sebestyen "New Architecture and Technology" Architectural Press, ISBN (0750651644), Oxford. 2003.

[25] Faten Fares Fouad, Nanoarchitecture and Sustainability, Department of Architecture Faculty of Engineering, University of Alexandria, (2012)

[26] Enrico Ercolani, Nanomaterial for Architecture, Department of Industrial Engineering , Via del Politecnico 1, 00133, Rome, Italy,

[27] Google Earth

\section{AUTHORS}

1. Prof . Sherif Kamal Desouky, Professor of Science and building Technology Department of Architecture Faculty of Engineering . University of Zagazig Scientific degrees

2 . Prof . Hussein Sabri El shanawani, Professor of Architecture and building Technology Science, Department of Architecture Faculty of Engineering, University of Zagazig Scientific degrees

3 . Dr. Razan Ibrahim Arafa Architecture Teacher Faculty of Engineering Zagazig University Scientific degrees

4 . Architect : Mai Mohammed Hamed , Lecturer, Department of Architecture The Higher Institute of Engineering and Technology in Obour. Bachelor of Architecture University of Zagazig - 2014 